\title{
The Impact of Nutritional Counseling to Nutritional Knowledge and Energy Intake among Obese Children in Junior High School
}

\author{
Lastri Asmuniati, ${ }^{1}$ Dewi Marhaeni Diah Herawati, ${ }^{2}$ Julistio T. B. Djais ${ }^{3}$ \\ ${ }^{1}$ Faculty of Medicine Universitas Padjadjaran, Indonesia, ${ }^{2}$ Department of Public Health \\ Faculty of Medicine Universitas Padjadjaran, Indonesia, ${ }^{3}$ Department of Child Health Faculty of \\ Medicine Universitas Padjadjaran/Dr. Hasan Sadikin General Hospital Bandung, Indonesia
}

\section{Abstract}

Background: Obesity has a serious impact on health, leading to not only premature mortality but also to long-term morbidity. Factors that contribute to obesity are genetic and lifestyle. This study aimed to analyze the impact of nutritional counseling on nutritional knowledge and energy intake among obese children in junior high school.

Methods: This quasi-experimental study was conducted in Jatinangor in September-November 2014 using a consecutive sampling until 25 students had reached. The inclusion criteria were junior high school students with BMI z-score per age $>2$ obese categories. Nutritional knowledge and energy intake were measured using a 24-hour recall test, conducted before and after 2 weeks of nutritional counseling. Data were analyzed using a paired t-test.

Results: The average of nutritional knowledge before counseling was $46.72 \pm 2.63$ and after counseling was $65.92 \pm 2.92(\mathrm{p}<0.001)$, whereas the average in energy intake before counseling was $1769.68 \pm 113.32$ and after counseling was $1397.52 \pm 114.31(\mathrm{p}=0.006)$.

Conclusions: There is an increase knowledge and decrease energy intake among obese children in junior high school students in Jatinangor subdistrict after nutritional counseling. A better understanding among obese children needs to be highlighted and nutrition education and counseling should be given in schools.

Keywords: Energy intake, counseling, nutrition, obesity

\section{Introduction}

Obesity is an excess of adipose tissue mass fat in the body, leading to health impairment. ${ }^{1}$ Obesity is a global problem that occurs in all age including childhood, adolescence, or adulthood. This condition has a serious impact on health, leading to not only premature mortality but may cause long-term morbidity such as diabetes, ischemic heart disease, cancer, and psychological problem. ${ }^{2}$ Obesity might be caused by an excess energy intake or a lack of energy expenditure or both; and influenced by genetic factor and environmental factors such as lifestyle, physical activity, nutrition, and socioeconomic factor. ${ }^{1}$

For the last thirty years, the prevalence of obesity is increased gradually. It is estimated that more than 170 million children are obese globally. ${ }^{2}$ The prevalence of obesity in Indonesia in 2007 is $12 \%$, and increased to $14 \%$ in $2010 .{ }^{3}$ National data shows that the highest prevalence of obesity is in children of age category of 6-12 years old, followed by age category of 13-15 years old. ${ }^{3}$ In our region Jatinangor, there is a shift from rural to urban; from the agricultural sector to the university area. ${ }^{4}$ This shift has led to a change of lifestyle in the communities that may play a role in obesity, including a changing in food intake in children in general and in obese children in particular, leading to an increased prevalence of obesity in the area. Therefore, we were interested in researching the impact of nutritional counseling on nutritional knowledge and the energy intake in obese

Correspondence: Lastri Asmuniati, Faculty of Medicine, Universitas Padjadjaran, Jalan Raya Bandung-Sumedang Km. 21, Jatinangor, Sumedang. E-mail: asmuniatilastri@gmail.com 
children junior high school in the area of the Jatinangor subdistrict.

\section{Methods}

This was a quasi-experimental study, involving students from 4 junior high schools in Jatinangor subdistrict. This study was conducted from September to November 2014. Participants were selected by consecutive probability sampling, with a total of 25 participants. The inclusion criteria were obese students with z-score WHO BMI per age $>2$ obese categories who were not on diet restriction program, healthy, willing to participate in the study and signing in the informed consent form.

The weight and height were measured and described in the z-score WHO BMI per age. The score of $>2$ to 3 was designated as obese, and $>3$ as very obese. The nutritional knowledge and 24-hour recall for energy intake questionnaires were asked before and after nutritional counseling, using an instrument. The post-test was performed 2 weeks after nutritional counseling.

Data were collected and analyzed statistically using paired t-test (SPSS 15.0), comparing the result of nutritional knowledge and energy intake before and after nutritional counseling. The result of the study was statistically significant if the p-value $<0.05$.

\section{Results}

Of twenty-five students aged 12-15 years old with obese included, girls were predominant (15 of $25 ; 60 \%)$ in the study. The distribution of students with obesity in this study was depicted in Table 1, based on gender and obesity categories.

The mean of nutritional knowledge was $46.72 \pm 2.63$ and $69.92 \pm 2.92$ before and after nutritional counseling, respectively, showed that there was a significant increased $(p<0.001)$ in knowledge after a session of nutritional counseling. Similarly, the energy intake before counseling was $1769.68 \pm 113.32$ and after
Table 1 The Distribution of Students with Obesity Based on Gender and Obesity Category

\begin{tabular}{lc}
\hline \multicolumn{1}{c}{ Variable } & Total (n=25) \\
\hline Gender & \\
Male & 10 \\
Female & 15 \\
Obesity category & \\
Obese $(>2$ to 3$)$ & 11 \\
Very obese $(>3)$ & 14 \\
\hline Note: The obesity category according to z-score WHO \\
BMI per age
\end{tabular}

was $1397.52 \pm 114.31$ which was significantly decreased $(p<0.006)$ after counseling.

\section{Discussion}

Children with obesity have a serious impact on health in a medium-term and also in the long term, resulting in a greater risk factor for the occurrence of cardiovascular disease for about 70 percent. Obese children are more likely to have pre-diabetes, the problem in bones and joints, shortness of breath during sleep, social and psychological problems, such as stigmatization and declining selfconfidence, ${ }^{5,6,7}$ Moreover, in the long term, these obese children are most likely will later become obese in adulthood and also have a higher risk factor for the occurrence of cancer. $^{8,9}$

Prevention of obesity complications requires behavioral changes especially food intake and physical activity. In this study, we provided data about the effect of counseling to change the energy intake in lifestyle and nutritional knowledge. Counseling could develop trust and build a good relationship between respondents of clients and counselor as such a study requires a considerable time and high intensity of conversation with the clients.

Table 2 The Nutritional Knowledge and The Energy Intake before and after Nutritional Counseling

\begin{tabular}{lccc}
\hline & \multicolumn{2}{c}{ Nutritional Counseling } & p-value \\
\cline { 2 - 3 } & Before & After & \\
\hline Knowledge & $46.72 \pm 2.63$ & $65.92 \pm 2.92$ & $<0.001$ \\
Energy intake & $1769.68 \pm 113.32$ & $1397.52 \pm 114.31$ & 0.006 \\
\hline
\end{tabular}


Our result has shown that nutritional counseling has increased the nutritional knowledge $(p<0.001)$, confirming that nutritional counseling has a good impact on knowledge as shown in a study conducted in Finlandia. ${ }^{10}$ As for the energy intake after nutritional counseling, there is a reduced intake $(p<0.006)$ showing that not only knowledge is increased but the intake is reduced conforming to the action of awareness and knowledge. Lower energy intake may in turn continually decrease BMI in obese children, as reported in a study showing an impact in decreasing BMI in obese individuals. ${ }^{11}$ As reported, most obese children is in girls similar to our study.

Interestingly, a study in Italy has observed a change of knowledge after nutritional education with Kalèdo's game methods in junior high school for 24 weeks. ${ }^{12}$ Study on younger students has been successfully achieved in Finland including children aged 7 to 9 years old, ${ }^{10}$ making that such a study might be double in Indonesia.

The limitation of this study was a time limit to observe changes energy intake in students after counseling. Ideally, the measurement of dietary intake changes may take place a minimal 12 weeks after intervention..$^{13}$ However, in only 2 weeks, there is already increasing in the energy intake that may, in turn, become a habit to lower the intake due to higher nutritional knowledge.

To conclude, after nutritional counseling there is an increased knowledge and decrease energy intake among obese children in junior high school students in the Jatinangor subdistrict. A better understanding among obese children starting at young age needs to be highlighted and nutrition education and counseling should be given in schools.

\section{References}

1. Spruitz-Metz D. Etiology, treatment and prevention of obesity in childhood and adolescence: A Decade in Review. J Res Adolesc. 2011; 21(1):129-52

2. WHO. Population-based approaches to childhood obesity prevention. Geneva: WHO Press; 2012.

3. Badan Penelitian dan Pengembangan Kesehatan. Riset kesehatan dasar Nasional. Jakarta : Kementerian Kesehatan Republik Indonesia; 2010.

4. BAPPEDA Kabupaten Sumedang. Laporan Akhir Studi Kelayakan Kawasan Jatinangor Sebagai Kawasan Perkotaan. Sumedang:
BAPPEDA KAbupaten Sumedang; 2009.

5. Freedman DS, Mei Z, Srinivasan SR, Berenson GS, Dietz WH. Cardiovascular risk factors and excess adiposity among overweight children and adolescents: the Bogalusa Heart Study. J Pediatr. 2007;150(1):12-7.

6. Daniels SR, Arnett DK, Eckel RH, Gidding SS, Hayman LL, Kumanyika S, et al. Overweight in children and adolescents: pathophysiology, consequences, prevention, and treatment. Circulation. 2005;111(15):1999-2012.

7. LiC, Ford ES, Zhao G, MokdadAH.Prevalence of pre-diabetes and its association with clustering of cardiometabolic risk factors and hyperinsulinemia among U.S. adolescents. Diabetes Care. 2009;32(2):342-7.

8. Freedman DS, Khan LK, Serdula MK, Dietz WH, Srinivasan SR, Berenson GS. The relation of childhood BMI to adult adiposity: the Bogalusa Heart Study. Pediatrics. 2005;115(1):22-7.

9. Kushi LH, Doyle C, McCullough M, Rock CL, Demark-Wahnefried W, Bandera EV, et al. American Cancer Society Guidelines on nutrition and physical activity for cancer prevention: reducing the risk of cancer with healthy food choices and physical activity. CA Cancer J Clin. 2012;62(1):30-67.

10. Rasanen M, Niinikoski H, Keskinen S, Heino T, Lagstrom H, Simell O, et al. Impact of nutrition counselling on nutrition knowledge and nutrient intake of 7- to 9 -y-old children in an atherosclerosis prevention project. Eur J Clin Nutr. 2004;58(1):162-72.

11. Cassani RSLCunhaSFC, Freitas ALG, Nonino CB, Marchini JS. Effects of nutritional counseling on the anthropometric and biochemical nutritional data of obese workers: a randomized blind study. Universal Journal of Clinical Medicine. 2013;1(1):6-12.

12. Amaro S, Viggiano A, Di Costanzo A, Madeo I, Viggiano A, Baccari ME, et al. Kalèdo, a new educational board-game, gives nutritional rudiments and encourages healthy eating in children: a pilot cluster randomized trial. Eur J Pediatr. 2006;165(9):630-5.

13. Brown T, Summerbell C. Systematic review of school-based interventions that focus on changing dietary intake and physical activity levels to prevent childhood obesity. The National Institute for Health and Clinical Excellence. 2009;10(1):110-41. 